\title{
Endotracheopulmonary Instillation, Solution Dosage Form
}

National Cancer Institute

\section{Source}

National Cancer Institute. Endotracheopulmonary Instillation, Solution Dosage Form. NCI

Thesaurus. Code C149492.

Liquid preparation consisting of an aqueous solution intended for instillation to the trachea and/or bronchi. 